\title{
Regulation of Scavenger Receptor, Class B, Type I, a High Density Lipoprotein Receptor, in Liver and Steroidogenic Tissues of the Rat
}

\author{
Katherine T. Landschulz, ${ }^{\star}$ Ravindra K. Pathak, ${ }^{\star}$ Attilio Rigotti, ${ }^{\ddagger}$ Monty Krieger, ${ }^{\ddagger}$ and Helen H. Hobbs ${ }^{\star}$ \\ *Departments of Internal Medicine and Molecular Genetics, University of Texas Southwestern Medical Center, Dallas, Texas 75235; and \\ ${ }^{\ddagger}$ Department of Biology, Massachusetts Institute of Technology, Cambridge, Massachusetts 02139
}

\begin{abstract}
The scavenger receptor, class B, type I (SR-BI) binds HDL and mediates the selective transfer of cholesteryl esters from HDL to cultured cells. The tissue distribution of SR-BI in mice suggests that this receptor may deliver HDL-cholesterol to the liver and to nonplacental steroidogenic tissues. To examine the role of SR-BI in vivo, we determined its tissue and cell type-specific expression pattern and regulation in rats. High levels of immunodetectable SR-BI were present in the adrenal gland, ovary, and liver. In pregnant animals, the mammary gland also expressed high levels of the protein. SR-BI was localized by immunofluorescence to the surfaces of steroidogenic cells in the zona fasciculata and zona reticularis of the adrenal gland and to the corpus luteal cells of the ovary. High-dose estrogen treatment dramatically reduced SR-BI in the liver and increased SR-BI in the adrenal gland and corpus luteal cells of the ovary. These estrogen-induced increases in SR-BI in the adrenal gland and ovary were accompanied by enhanced in vivo uptake of fluorescent lipid from HDL. The administration of human chorionic gonadotropin induced a dramatic increase in SRBI in the steroidogenic Leydig cells of the testes. These findings suggest that SR-BI mediates physiologically relevant uptake of cholesterol from HDL to nonplacental steroidogenic tissues in vivo. (J. Clin. Invest. 1996. 98:984995.) Key words: high density lipoprotein • receptor • estrogen $•$ human chorionic gonadotropin $\bullet$ rats
\end{abstract}

\section{Introduction}

The strong inverse relationship between plasma levels of high density lipoprotein-cholesterol (HDL-C) $)^{1}$ and coronary artery disease has stimulated a search for the cellular mechanisms responsible for HDL metabolism (1). HDL has been implicated in mediating the removal of cholesterol from cells as well as the transport and uptake of cholesterol by the liver and other

Address correspondence to Helen H. Hobbs, Department of Molecular Genetics, UT Southwestern Medical Center, 5323 Harry Hines Blvd., Dallas, TX 75235-9046. Phone: 214-648-6724; FAX: 214-6487539.

Received for publication 2 May 1996 and accepted in revised form 21 June 1996.

1. Abbreviations used in this paper: $\mathrm{C}$, cholesterol; DiI, 3,3' dioctadecylindocarbocyanine; ECL, enhanced chemiluminescence detection; hCG, human chorionic gonadotropin; LDLR, LDL receptor; SR-BI, scavenger receptor, class $\mathrm{B}$, type I; RAP, receptor-associated protein.

J. Clin. Invest.

(C) The American Society for Clinical Investigation, Inc. 0021-9738/96/08/0984/12 \$2.00

Volume 98, Number 4, August 1996, 984-995 selected tissues (1). A cDNA encoding a cell surface protein that binds HDL was recently cloned and characterized (2-4). This cDNA was initially isolated because of the ability of the encoded protein to bind modified LDL. Multiligand, cell surface receptors for modified lipoproteins are called scavenger receptors, and this protein was named the scavenger receptor, class B, type I (SR-BI) (2). In addition to binding modified LDL, SR-BI can bind native LDL and anionic phospholipids $(2,3)$. Expression of the SR-BI cDNA in transfected cells confers high affinity, saturable binding of ${ }^{125}$ I-labeled HDL and stimulates transfer of $\left[{ }^{3} \mathrm{H}\right]$ cholesteryl oleate from HDL to cells (4). The mechanism by which HDL-C is delivered to cells differs from the well-characterized LDL receptor (LDLR)-mediated cholesterol (C) transport system (5). LDL binds to the LDLRs on the cell surface, and the receptor-LDL complex is internalized by receptor-mediated endocytosis via clathrincoated vesicles to endosomes. LDL dissociates from the receptor in endosomes and then is delivered to lysosomes where its protein component, apo B100, is degraded and core cholesteryl esters are hydrolyzed to cholesterol and fatty acids. In contrast, SR-BI-mediated uptake of cholesteryl esters from HDL is not associated with significant degradation of apo AI or apo AII, the two major apolipoproteins of HDL. Preliminary studies indicate that lipid transferred from HDL to the cells is initially found in the plasma membrane (4, also see references 6 , 7), but the precise intracellular fate of the HDL-derived lipid is not known. SR-BI-mediated processing of LDL cholesterol has not yet been well defined and is currently under investigation.

The selective delivery of the lipid, but not the protein component from HDL to cells, is a mechanism used by rodents to deliver cholesterol esters to the liver (8). In rats, the liver clears $\sim 65 \%$ of HDL cholesteryl esters from the plasma pool via the selective uptake mechanism (9). Once in the hepatocyte, the HDL-derived cholesteryl esters are either secreted into the bile, used to synthesize bile acids, or packaged with other lipids and proteins to form VLDLs (1). The transport of HDL-C from extrahepatic tissues to the liver has been called reverse cholesterol transport (10-12), which is believed to play a crucial role in the distribution of cholesterol throughout the body, and presumably, in the regulation of cholesterol metabolism.

In rodents, HDL also transports cholesteryl esters to the adrenal gland, ovary, and testes $(8,9,13,14)$ for steroidogenesis. Almost 20 yr ago, Balasubramaniam, Brown, and Goldstein $(15)$ and Andersen and Dietschy $(16,17)$ showed that intravenous infusion of HDL and LDL can suppress sterol synthesis in the adrenal gland of the rat. Similar findings were subsequently reported for the ovary and testes of hypocholesterolemic rats (14). In rodents, some of the HDL particles contain apo E and thus can bind to the LDLR and be internalized by receptor-mediated endocytosis. However, Kovanen et al. demonstrated independent mechanisms for the uptake of cholesterol from LDL and apo E-free HDL in the mouse adrenal gland (18). Most of the HDL cholesteryl ester uptake by the 
rat adrenal gland, ovary, and liver is not associated with degradation of apo AI, as would be expected if the particles were metabolized by LDLR-mediated endocytosis. Rather, the lipids are selectively transferred to the cells independently of the apolipoproteins (7-9, 19-21). These studies suggest that a protein serving as an HDL receptor should be expressed at significant levels in the liver and steroidogenic tissues of rodents. Immunoblot analysis of murine tissues using an SR-BI-specific antibody revealed that this receptor exhibits the expected tissue-specific expression pattern (4). The highest levels of immunodetectable SR-BI protein are in the murine adrenal gland and ovary, with lower levels detected in the liver and small amounts in the testes (4). Little or no SR-BI is present in the placenta, the other major steroidogenic tissue in the mouse.

If SR-BI mediates selective HDL (and possibly LDL) cholesterol uptake (22) in vivo, one might expect the levels of SR-BI protein to be regulated by physiologic and pharmacologic stimuli that alter sterol metabolism in the tissues expressing this receptor. We have investigated two such stimuli, estrogen and human chorionic gonadotropin (hCG). In humans, estrogen contributes to the reduction in cardiac risk enjoyed by premenopausal women (23). The molecular mechanisms underlying the protective effects of estrogen have not been defined precisely, but some of the effect has been attributed to an estrogen-induced reduction in plasma LDL-C and an increase in plasma HDL-C levels (24). In rats, high-dose estrogen treatment dramatically lowers the plasma concentrations of both LDL and HDL $(25,26)$. Estrogen administration is associated with a pronounced increase in hepatic $\operatorname{LDLR}$ activity $(27,28)$ resulting in an increase in the plasma clearance of LDL and apo E-containing $\operatorname{HDL}(28,29)$. Estrogen administration is also associated with an increase in selective uptake of HDL cholesteryl ester by the rat adrenal gland and ovary (30). Hormonal induction of steroidogenesis in vivo, such as hCG stimulation of testicular and ovarian steroidogenesis and ACTH stimulation of adrenal cortical steroidogenesis, has also been shown to increase HDL binding to stimulated tissue $(31,32)$ and to be associated with increased cholesterol uptake (3335). If SR-BI plays a significant role in providing substrate for hormonally induced steroidogenesis, hormones such as hCG and ACTH are likely to specifically induce increased expression of SR-BI protein in their target tissues.

In this paper, we used immunoblotting and immunolocalization techniques to examine the tissue and cell-type specificity of SR-BI expression in rodents and the effects of both high-dose estrogen treatment and exposure to hCG on this expression. We found that the tissue-specific expression pattern of SR-BI in rats was similar to that in mice (4). High levels of SR-BI were found in the adrenal gland, ovary, and liver. Estrogen dramatically altered the levels of SR-BI in these three tissues; the direction of the estrogen-induced changes paralleled known effects of estrogen on the rate of selective tissue uptake of HDL-cholesteryl esters in these tissues (30). In addition, we found that hCG administration dramatically increased the levels of SR-BI in the Leydig cells of the testes. These observations provide strong evidence that SR-BI is regulated in vivo and supports our proposal that SR-BI is a physiologically relevant HDL receptor (4).

\section{Methods}

Materials. 17 $\alpha$-ethinyl estradiol, propylene glycol, and hCG were obtained from Sigma Chemical Co. (St. Louis, MO). HDL was pre- pared from human plasma by zonal centrifugation (4) and labeled with 3,3'-dioctadecylindocarbocyanine (DiI) from Molecular Probes, Inc. (Eugene, OR) as described (36). Labeled HDL preparations, which contained no detectable apo $\mathrm{E}$ by Coomassie staining, were extensively dialyzed against normal saline before injection into animals.

Animals. Male and female 1-3-mo-old Sprague-Dawley rats weighing 100-225 grams were obtained from Harlan Laboratories (Gilmore, CA). The animals were housed at $22^{\circ} \mathrm{C}$ under a constant light-dark cycle (6:00 a.m. to 6:00 p.m.) with ad libitum access to water and rodent chow (Teklad Premier Laboratory Diets, Madison, WI). Estrogen-treated rats were injected subcutaneously for $5 \mathrm{~d}$ consecutively with $5 \mathrm{mg} / \mathrm{kg}$ body weight of $17 \alpha$-ethinyl estradiol in propylene glycol (10 mg/ml) (Sigma Chemical Co.). Control animals were injected with an equivalent volume of propylene glycol alone. The mean weight loss of the male and female estrogen-treated animals was $18 \pm 8$ and $10 \pm 4$ grams, respectively, whereas in the shaminjected animals there was an increase of $12 \pm 7$ grams in the males and $6 \pm 3$ grams in the females. Rats treated with hCG were injected subcutaneously with $250 \mathrm{U} / \mathrm{kg}$ body weight in buffer A $(10 \mathrm{mg} / \mathrm{ml}$ mannitol, $10 \mathrm{mM}$ sodium phosphate, $\mathrm{pH}$ 7.2) for $4 \mathrm{~d}$ while control animals received an equivalent volume of buffer A only. For immunofluorescence studies, the animals were fasted overnight (12-20 h) before death.

Immunoblot analysis of rat tissues. Membrane fractions were prepared from pulverized rat tissue that had been frozen in liquid $\mathrm{N}_{2}$ immediately after harvesting and stored at $-80^{\circ} \mathrm{C}(37)$. The membranes were resuspended under reducing conditions and $50 \mu \mathrm{g}$ of protein was size fractionated on $6.5 \%$ SDS-polyacrylamide gels. Cellular extracts from ldlA [mSR-BI] cells, a Chinese hamster ovary (CHO) cell line expressing murine SR-BI (4) and untransfected cells served as positive and negative controls. Immunoblot analysis was performed using a polyclonal rabbit antipeptide antibody ( $\operatorname{IgG}-495)$ raised against the last 14 amino acids of the mouse SR-BI (4). An identical protocol was used for immunoblot analysis of the LDLR and receptor-associated protein (RAP), except the gels were run under nonreducing conditions and IgG-713, a polyclonal rabbit anti-bovine LDLR antibody (38), or IgG-692, a polyclonal rabbit anti-rat RAP antibody (39), was used.

Plasma apo AI and apo E levels were assessed qualitatively by electrophoretically size-fractionating plasma proteins on SDS-polyacrylamide $3-15 \%$ gradient gels and immunoblotting using rabbit anti-rat apo AI and apo E antisera (40). All blots were subjected to enhanced chemiluminescence detection (ECL; Amersham Corp., Arlington Heights, IL) and exposed to Kodak Dupont NEF 496 film (Wilmington, DE) at room temperature. The relative intensities of the bands were determined using a Hewlett-Packard Scan Jet 3c/T (Hewlett-Packard Co., Palo Alto, CA) scanner and NIH Image version 1.59 software.

RNA blot analysis. Frozen tissue samples were pulverized and total cellular RNA was isolated as previously described (37). An aliquot of $20 \mu \mathrm{g}$ of total cellular RNA was size fractionated on a $1 \%$ (wt/ $\mathrm{vol})$ agarose, $2 \%(\mathrm{vol} / \mathrm{vol})$ formaldehyde gel, transferred to a nylon membrane and then probed with a $750-b p{ }^{32} \mathrm{P}$-labeled murine SR-BI cDNA probe and subsequently with an end-labeled oligonucleotide complementary to the $28 \mathrm{~S}$ ribosomal RNA: (5'- GGGAAACTTCGGAGGGAACCAGCTA - 3').

FPLC analysis of plasma lipoproteins. Plasma pooled from two male rats was collected and subjected to Superose 6 gel filtration by fast performance liquid chromatography (FPLC); the cholesterol content of each fraction was assayed by spectrofluorometry (41).

Immunofluorescence microscopy of selected rat tissues. Rats were anesthetized with nembutal and perfused at room temperature through the left ventricle with $120 \mathrm{ml}$ of oxygenated HBSS and then with $120 \mathrm{ml}$ of $3 \%$ (vol/vol) paraformaldehyde. Tissues were removed, refixed, and processed for paraffin embedding as previously described (42). Deparaffinized sections were sequentially incubated in the following solutions at room temperature: buffer A $(200 \mathrm{mM}$ $\mathrm{NaCl}, 1 \mathrm{mM} \mathrm{MgCl}_{2}, 0.5 \mathrm{mM} \mathrm{KCl}, 20 \mathrm{mM}$ Tris-HCI [pH 9.0], and $1 \%$ 


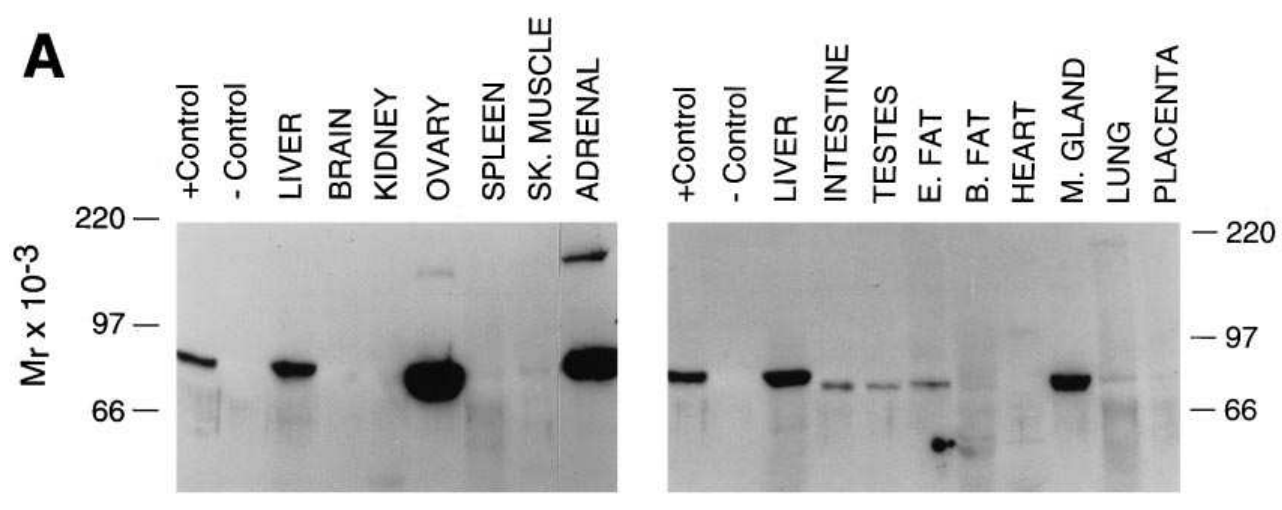

Figure 1. (A) Immunoblot analysis of the tissue distribution of rat SR-BI protein. A total of 50 $\mu \mathrm{g}$ of solubilized membrane proteins from various rat tissues were size fractionated on $6.5 \%$ (wt/vol) SDS-polyacrylamide gels under reducing conditions, transferred to nitrocellulose, and immunoblotted with a polyclonal anti-SR-BI antibody (IgG-495). The blot was incubated with horseradish peroxidase-conjugated sheep antirabbit IgG and developed using the ECL detection system (Amersham Corp.). Molecular mass

B
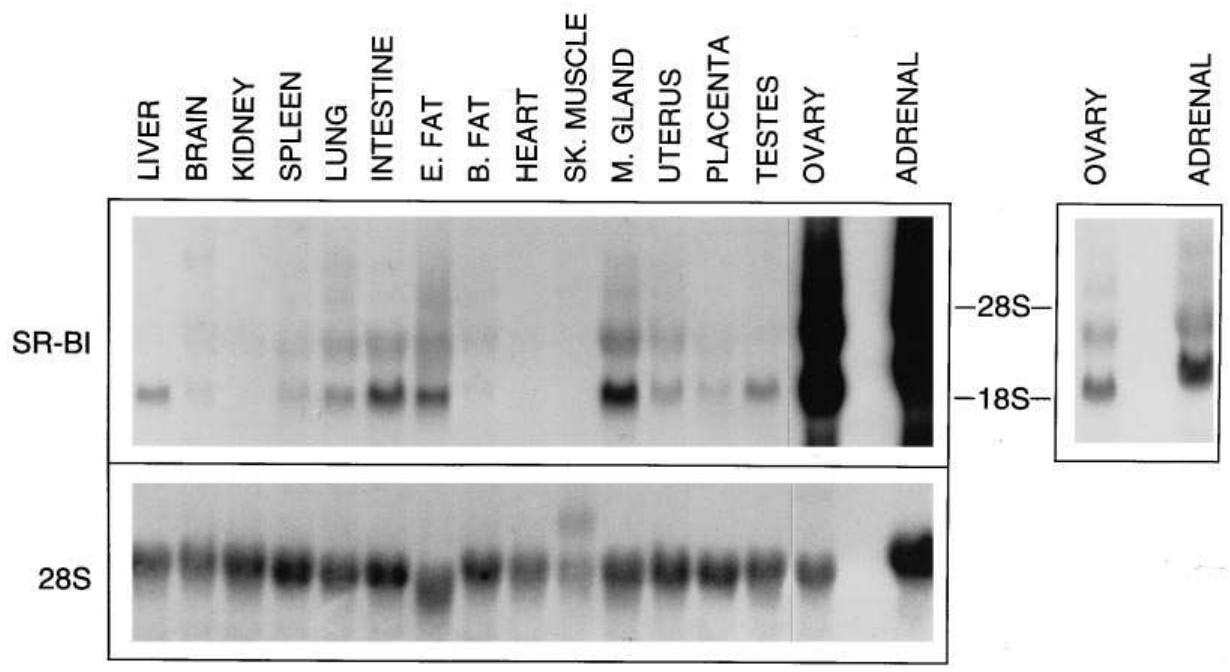
standards included myosin, 220 $\mathrm{kD}$; phosphorylase $\mathrm{B}, 97.4 \mathrm{kD}$; and bovine serum albumin, 66 $\mathrm{kD}$ (Amersham Corp.). A total of $50 \mu \mathrm{g}$ of cellular extract from ldlA7 cells expressing recombinant mSR-BI (2) was loaded as a positive $(+)$ control. Nontransfected ldlA7 cells were used as a negative (-) control. (B) Tissue distribution of rat SR-BI mRNA. Total RNA (20 $\mu \mathrm{g})$ from rat tissues was prepared as described under Methods and subjected to size fractionation on a $1 \%(\mathrm{wt} / \mathrm{vol})$ agarose, $2 \%(\mathrm{vol} / \mathrm{vol})$ formaldehyde gel. The RNA was transferred to a nylon membrane and hybridized with a 750-bp ${ }^{32} \mathrm{P}-$ labeled murine SR-BI cDNA probe (upper panels). The same filter was stripped and rehybridized with an endlabeled oligonucleotide probe complementary to $28 \mathrm{~S}$ rRNA (lower panel). The upper panel and lower panel were exposed for $72 \mathrm{and} 8 \mathrm{~h}$, respectively, with an intensifying screen. Due to the higher signal in the ovary and adrenal gland, a shorter $(14 \mathrm{~h})$ exposure time for these two tissues is also shown. The position of $18 \mathrm{~S}$ and $28 \mathrm{~S}$ rRNA species served as size markers to estimate the sizes of the SR-BI mRNA species. All RNAs except mammary gland, uterus, placenta, ovary, and adrenal gland were derived from male rat tissues. SK. MUSCLE, skeletal muscle; E. FAT, epididymal fat; $B$. FAT, brown fat; $M$. GLAND, pregnant mammary gland.

[wt/vol] bovine serum albumin) for $15 \mathrm{~min}$, buffer A plus $80 \mu \mathrm{g} / \mathrm{ml}$ of a polyclonal antibody (IgG-495, IgG-713, IgG-anti-apo AI, IgG-nonimmune) and finally, $15 \mu \mathrm{g} / \mathrm{ml}$ of fluorescein-conjugated goat antirabbit IgG (Zymed, San Francisco, CA) in buffer A for $2 \mathrm{~h}$. The sections were then washed twice for $5 \mathrm{~min}$ in buffer $\mathrm{A}$ and rinsed in distilled water before mounting in Slowfade ${ }^{\mathrm{TM}}$ (Molecular Probes, Inc., Eugene, OR). For analysis of DiI-HDL uptake in vivo, animals were anesthetized with nembutal or metafane before injection of DiI-HDL $(800 \mu \mathrm{g}$ protein $/ \mathrm{kg})$ into the left jugular vein. $1 \mathrm{~h}$ later the anesthetized animals were perfused as described above. Frozen sections (12 $\mu \mathrm{m}$ thick) of sucrose-infiltrated tissues were prepared as reported previously (43). Tissue sections were viewed and photographed with a Zeiss photomicroscope III (Carl Zeiss, Inc., Thornwood, NY) with the appropriate filter package for fluorescein (for immunofluorescence) or rhodamine (for DiI).

\section{Results}

Tissue distribution of rat SR-BI. Fig. 1 shows an immunoblot analysis of SR-BI (Fig. $1 A$ ) and Northern blot analysis of SR-BI mRNA (Fig. $1 B$ ) in selected rat tissues. Equal amounts (50 $\mu \mathrm{g}$ ) of membrane protein from various rat tissues were size fractionated on an SDS-polyacrylamide gel and SR-BI was de- tected with a rabbit anti-murine SR-BI polyclonal antibody (IgG-495) (Fig. $1 A$ ). As previously observed for murine SR-BI in transfected $\mathrm{CHO}$ cells (Fig. $1 A$, left lane) and murine tissues (4), the antibody recognized a protein with an apparent molecular mass of $\sim 82 \mathrm{kD}$. The adrenal gland and ovary had the highest levels of SR-BI. In addition to the $82-\mathrm{kD}$ band, a larger band of approximately twice this mass $(\sim 164 \mathrm{kD})$ was detected in these two high-expressing tissues. This larger band may represent a cross-reacting protein, a dimer of SR-BI, or a complex of SR-BI with other cellular components. The liver contained moderate amounts of SR-BI, as did the mammary gland of the pregnant rat. Only trace amounts of immunodetectable SR-BI were present in mammary tissue from nonpregnant animals (data not shown). Low levels of SR-BI were present in the intestines, testes, and epididymal (white) fat, and little or no SR-BI was present in the brain, kidney, spleen, skeletal muscle, brown fat, lung, and placenta. A faint protein of $\sim 129 \mathrm{kD}$, which may be a cross-reacting protein or an alternative form of SR-BI, was visible in the heart.

Northern blot analysis showed that the high levels of SR-BI protein in the adrenal gland and ovary were accompanied by comparable levels of the corresponding mRNA in these tissues 
A

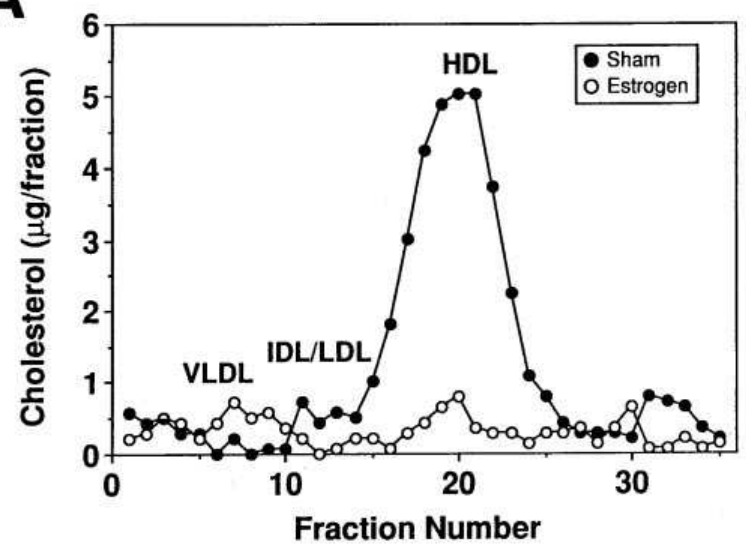

B

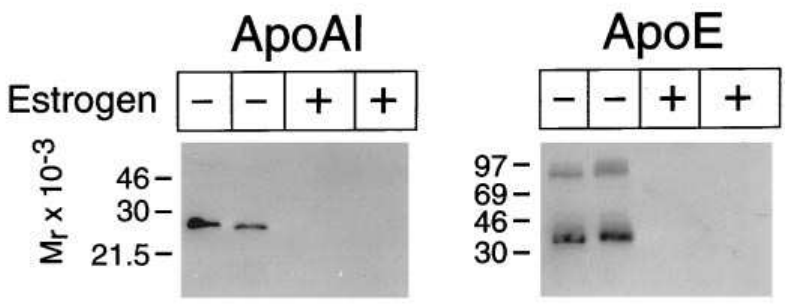

Figure 2. Lipoprotein distribution of plasma cholesterol $(A)$ and plasma apo $\mathrm{AI}$ and apo $\mathrm{E}(B)$ in rats with and without estrogen treatment. $(A)$ Plasma samples obtained from two adult male Sprague-Dawley rats treated for $5 \mathrm{~d}$ consecutively with $5 \mathrm{mg} / \mathrm{kg} 17 \alpha$-ethinyl estradiol (open circles) or two animals treated with an equivalent volume of propylene glycol carrier (filled circles) were pooled and subjected to FPLC Superose 6 gel filtration. The fractions were collected and assayed for cholesterol content (41). VLDL, IDL/LDL, and HDL indicate column elution positions of very low density lipoprotein, intermediate and low density lipoprotein, and high density lipoprotein. (B) Plasma from four male rats were analyzed for apo AI and apo E content by size fractionating $5.0 \mu \mathrm{l}$ of rat plasma on a $3-15 \%$ gradient polyacrylamide-SDS gel and immunoblotting with polyclonal anti-rat apo AI and apo E antisera (40). Lanes 1 and 2 contain plasma from animals injected with propylene glycol and lanes 3 and 4 plasma from animals treated with $17 \alpha$-ethinyl estradiol.

(Fig. 1, B). The most prominent mRNA was $\sim 2.4 \mathrm{~kb}$ in length, which is similar to that detected in murine tissues (2). An mRNA of similar size was detected using a 250-bp probe from the 3 ' end of the murine SR-BI cDNA (data not shown). In some tissues, an additional, as yet uncharacterized band of $\sim 3.8 \mathrm{~kb}$ was also detected. Due to the very high levels of expression of SR-BI mRNA in the ovary and adrenal gland, a fivefold shorter exposure time for these two samples is also shown (Fig. $1 \mathrm{~B}$, right). Although the size of the SR-BI mRNA in the adrenal gland appeared to be larger than that seen in the other lanes, this apparent difference in mobility appears to be caused by an edge effect on this particular gel. This difference was not observed in several other experiments (data not shown). In intestines and epididymal fat, there was proportionally more SR-BI mRNA than SR-BI protein. In contrast, the relative amount of mRNA in the liver was lower than expected for the level of immunodetectable protein (Fig. $1 A$ ). To ensure that the amount of protein detected in these membrane fractions reflected the total amount of cellular SR-BI, we repeated the immunoblot using whole cell extracts and obtained

Table I. Plasma Lipid Levels in Adult Male and Female Sham-injected and Estrogen-treated Rodents

\begin{tabular}{lllllll}
\hline & & \multicolumn{2}{c}{ Sham-injected } & & \multicolumn{2}{c}{ Estrogen-treated } \\
\cline { 3 - 4 } Species & Sex & Cholesterol & Triglycerides & & Cholesterol & Triglycerides \\
\hline & & $m g / d l$ & $m g / d l$ & & $m g / d l$ & $m g / d l$ \\
Rat & Males $(n=7)$ & $71 \pm 18$ & $35 \pm 7$ & & $4 \pm 3$ & $21 \pm 14$ \\
Rat & Females $(n=7)$ & $71 \pm 13$ & $63 \pm 15$ & & $15 \pm 8$ & $22 \pm 5$
\end{tabular}

Animals were treated with and without estrogen as described in Methods. Plasma cholesterol and triglyceride levels were quantitated using commercial kits from Boehringer Mannheim and Sigma Chemical Co., respectively. Values are expressed as mean \pm standard deviation. similar results (data not shown). Thus, the discrepancies between the steady-state levels of the SR-BI protein and mRNA observed in some tissues were not due to undetected SR-BI protein present in other cell fractions, but rather to tissue-spe-

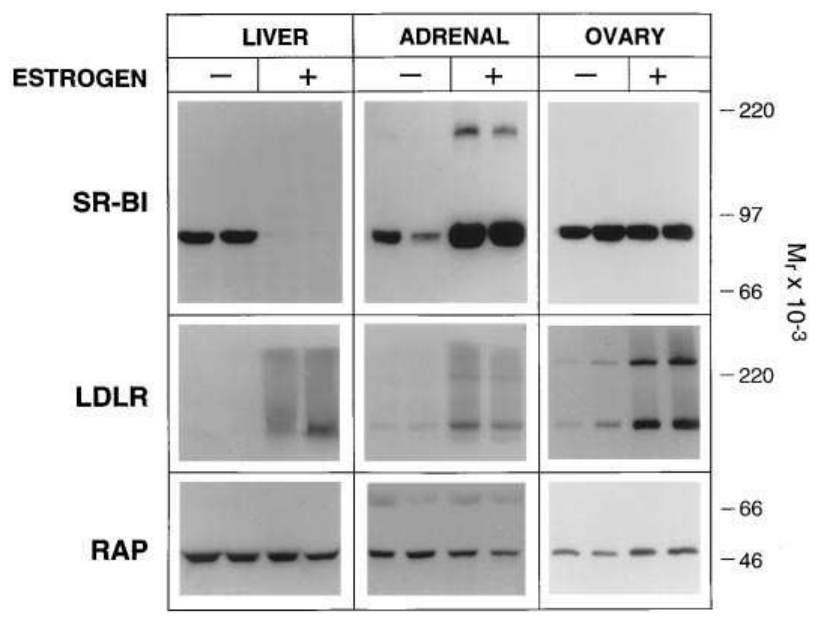

Figure 3. Immunoblot analysis of SR-BI, LDLR, and RAP in membrane proteins from tissues of sham-injected and estrogen-treated rats. Immunodetectable SR-BI protein was analyzed in membrane fractions of liver, adrenal gland, and ovary from animals treated with $(+)$ or without $(-) 17 \alpha$-ethinyl estradiol using rabbit anti-mouse SRBI (upper row). The same fractions were analyzed for LDLR content by immunoblotting with a cross-reacting rabbit anti-bovine LDLR antibody (middle row), and for RAP using a rabbit anti-rat RAP antibody (bottom row). All blots were developed using ECL (Amersham Corp.) and the exposure times were as follows: upper row liver; $2 \mathrm{~min}$; adrenal and ovary $10 \mathrm{~s}$; middle row - all $5 \mathrm{~s}$; lower row: liver, $15 \mathrm{~s}$, adrenal and ovary, $30 \mathrm{~s}$. Molecular mass standards were identical to those used in Fig. 1. 


\section{ESTROGEN -}
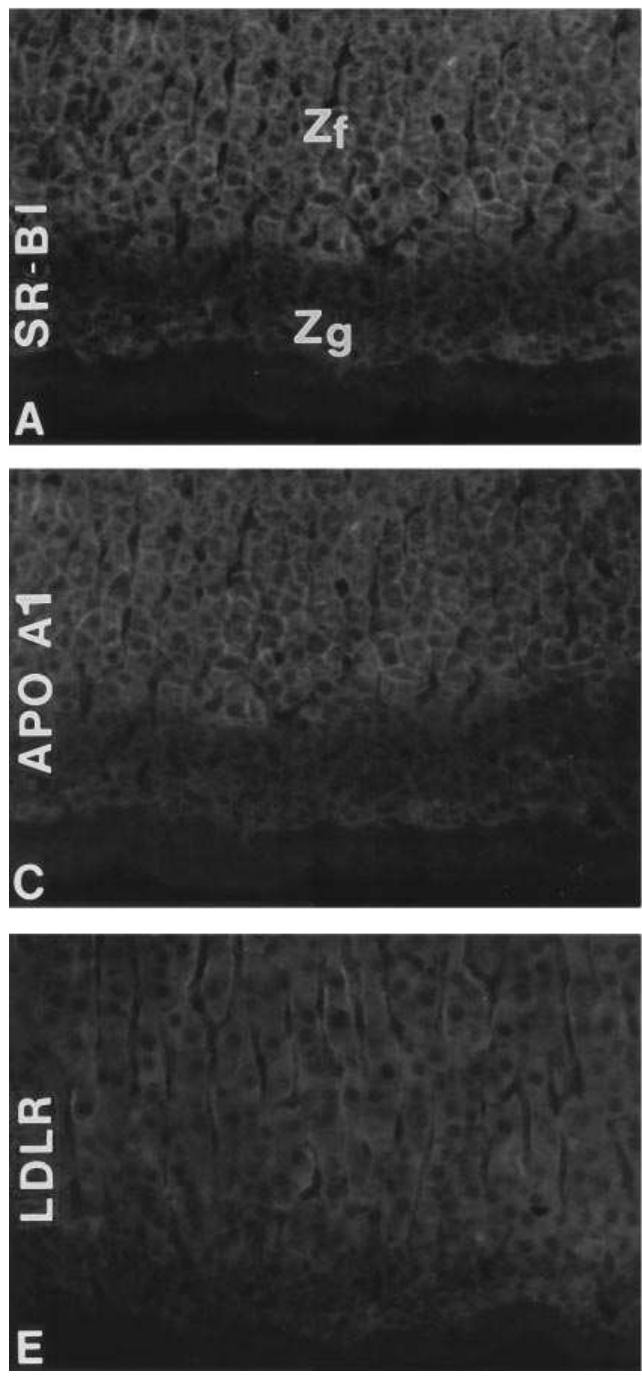

ESTROGEN +
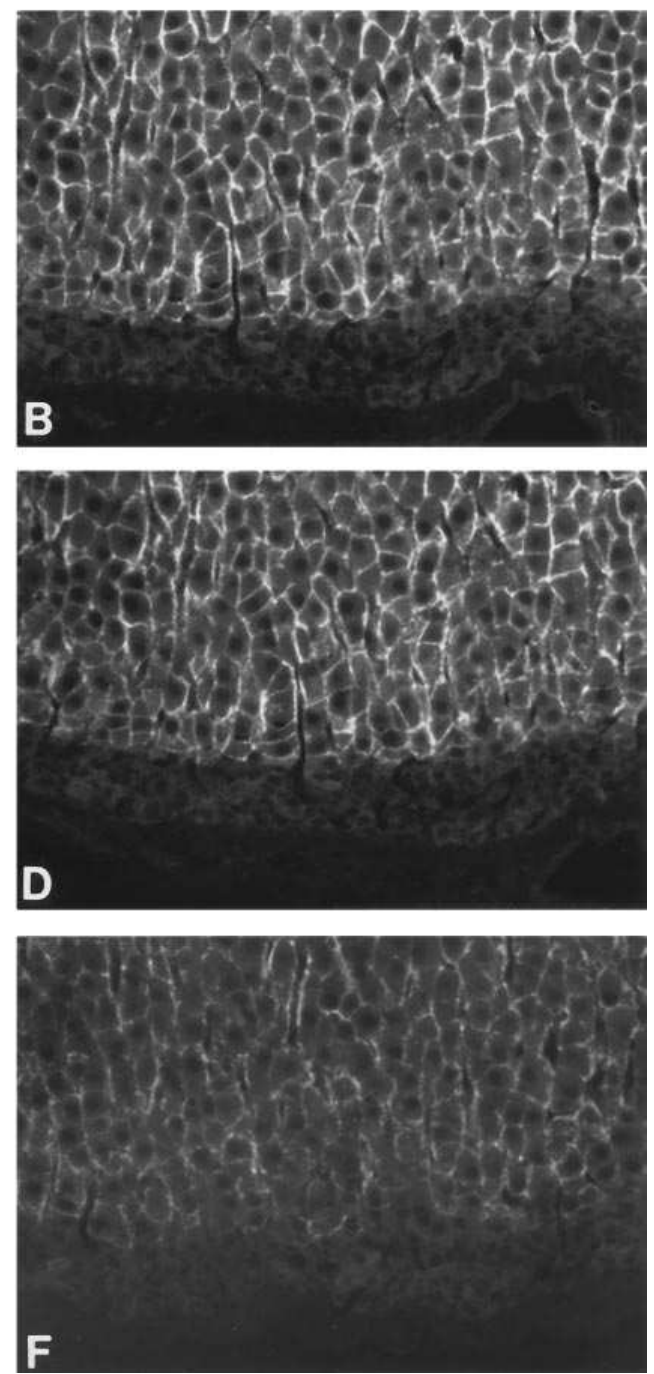

Figure 4. Immunolocalization of SR-BI, apo AI, and LDLR in the adrenal glands of sham $(A$, $C$, and $E$ ) and estrogen-treated $(B, D$, and $F)$ rats. Sections were incubated with either anti-SR-BI ( $A$ and $B$ ), or anti-apo $\mathrm{AI}(C$ and $D)$, or with anti-LDLR antibody $(E$ and $F$ ) followed by FITClabeled anti-rabbit IgG, as described in the Methods. $Z f$, zona fasciculata. $Z g$, zona granulosa. $\times 900$. cific, posttranscriptional regulation of SR-BI expression. Taken together, the data in Fig. 1 show that the primary sites of SR-BI expression in rats are the nonplacental steroidogenic tissues (especially the adrenal gland and ovary), liver, and the mammary gland during pregnancy.

Estrogen effects on SR-BI expression. The finding of an increased level of SR-BI expression in the mammary gland during pregnancy suggested there may be hormonal, particularly estrogen mediated, regulation of SR-BI expression in some tissues. To examine the effects of pharmacologic doses of estrogen on SR-BI expression, rats were treated with $5 \mathrm{mg} / \mathrm{kg}$ of ethinyl estradiol for $5 \mathrm{~d}$. Prior studies had shown that highdose estrogen therapy results in a dramatic decrease in the levels of plasma lipoproteins in the rat $(25,26)$. After $5 \mathrm{~d}$ of estrogen treatment, the mean plasma cholesterol levels fell from 71 to $4 \mathrm{mg} / \mathrm{dl}$, and triglyceride levels decreased from 35 to $21 \mathrm{mg} /$ $\mathrm{dl}$ in male animals (Table I). Similar changes were seen in the females (Table I). The lipoprotein profiles of pooled plasma samples from male rats before and after estrogen treatments (Fig. $2 A$ ) showed a modest increase in the plasma cholesterol in the VLDL fraction, a fall in the IDL/LDL fraction, and a dramatic decrease in the HDL fraction. Coincident with the decrease in plasma HDL-cholesterol, the plasma levels of two of the major apolipoproteins of rat HDL, apo AI, and Apo E, fell to nearly undetectable levels (Fig. $2 \mathrm{~B}$ ).

Fig. 3 shows the effect of high-dose estrogen treatment on the levels of immunodetectable SR-BI, LDLR, and RAP in the liver, adrenal, and ovary of the adult rat. RAP is a protein that binds to the LDLR-related protein $(L R P)$, a cell surface receptor that binds chylomicrons and other ligands (44). We used it here as an unregulated control. Due to the $\sim 25$-fold higher levels of SR-BI in the adrenal gland and ovary relative to the liver, the exposure times for the immunoblots were varied so that the intensity of the signals in the sham-injected animals were similar in all three tissues. In the liver, the amount of immunodetectable SR-BI protein was reduced by $>95 \%$ after estrogen administration. The decrease in SR-BI cannot be attributed to a general hepatotoxic effect of estrogen since it was associated with the well-established estrogen-induced increase in the level of LDLR (27). Moreover, no appreciable changes were detected in the levels of RAP in treated and control animals. In the adrenal gland, estrogen induced an elevation in both SR-BI (4-fold) and the LDLR ( 10-fold). The higher molecular weight, possibly oligomeric, form of SR-BI 
ESTROGEN -
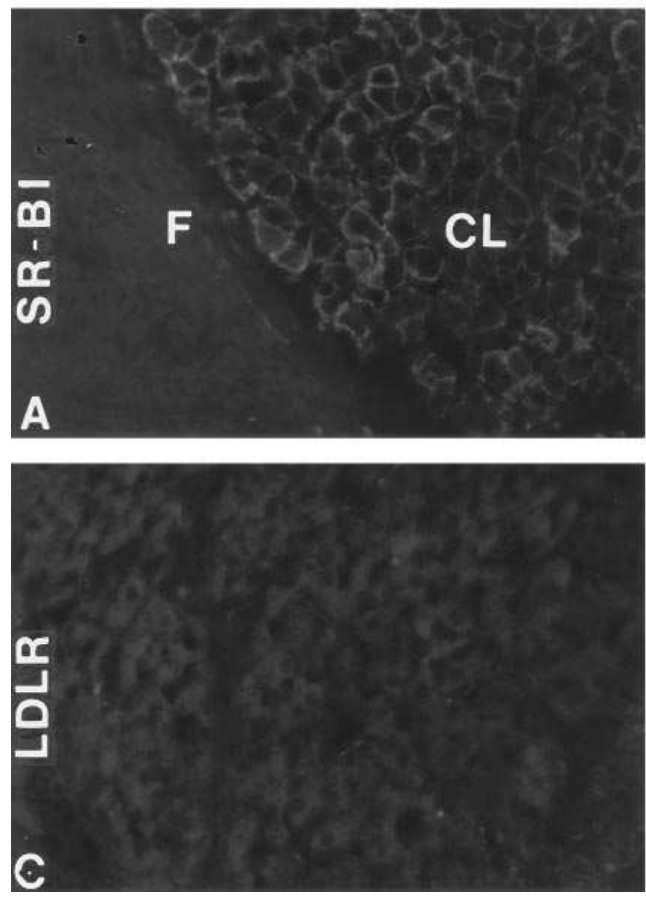

ESTROGEN +
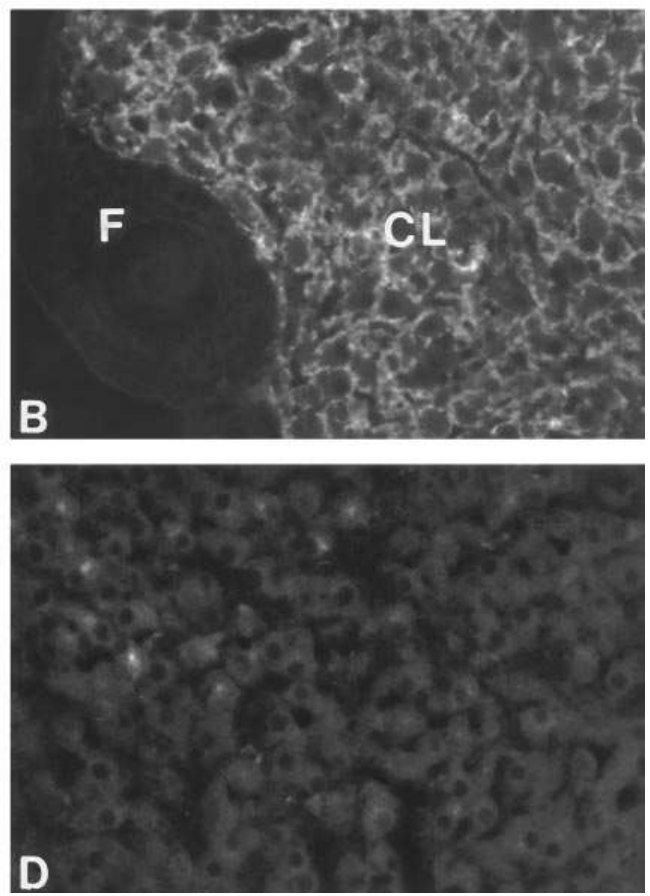

Figure 5. Immunolocalization of SR-BI and LDLR in the ovaries of sham $(A$ and $C)$ and estrogen-treated $(B$ and $D)$ female rats. Sections were immunostained as described in Fig. 4 with either anti-SR-BI $(A$ and $B$ ), or anti-LDLR antibody $(C$ and $D) . F$, follicle, $C L$, corpus luteum. $\times 900$. appeared after stimulation. In contrast to the adrenal gland in which the levels of both SR-BI and LDLR increased after estrogen treatment, no change was seen in the amount of ovarian SR-BI. There was, however, a fourfold increase in the amount of LDLR in the ovary. We also examined SR-BI levels in adipose tissue, kidney, heart, testes, and muscle, and no significant estrogen-dependent changes were detected in these tissues (data not shown).
Localization of SR-BI expression in tissues. To determine which cell types express SR-BI in the adrenal gland, ovary, and liver, we performed indirect immunofluorescence localization studies with an anti-SR-BI antibody in sham-injected and estrogen-treated animals. In the adrenal gland of the control animals (Fig. 4), cell surface staining was visible in the zona fasciculata $(Z f)$ and reticularis (not shown), the two major sites of steroidogenesis in the rat adrenal gland. Much less staining
ESTROGEN -
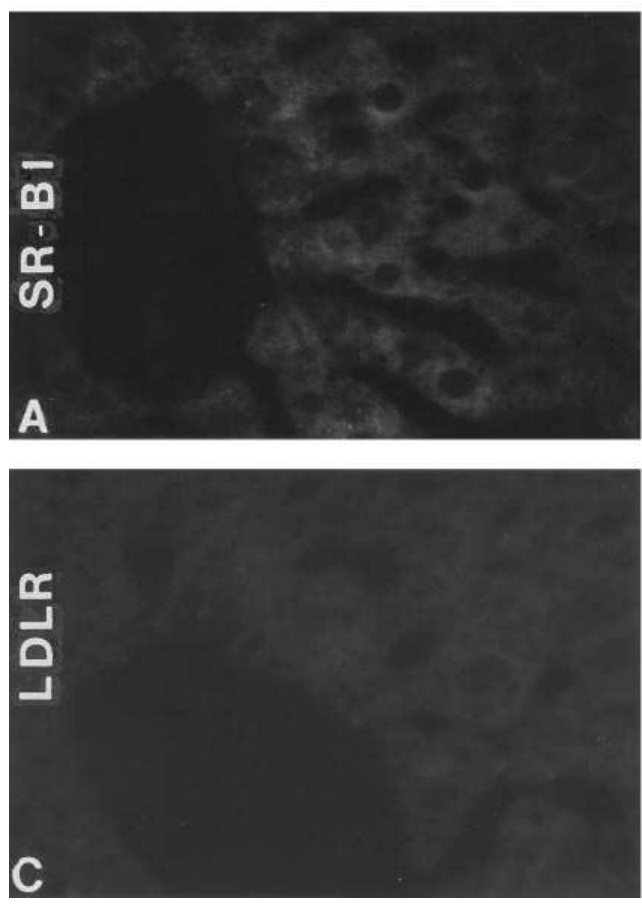

ESTROGEN +
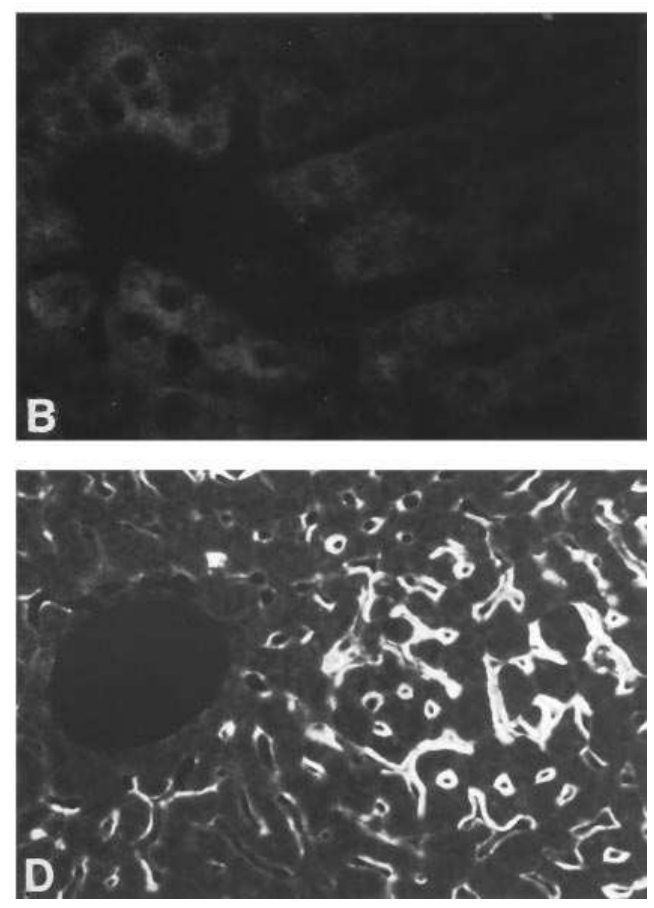

Figure 6. Immunolocalization of SR-BI and the LDLR in the livers of sham $(A$ and $C)$ and estrogen-treated rats $(B$ and $D)$. Paraffin sections of perfused fixed livers were incubated with antiSR-BI $(A$ and $B)$ or with antiLDLR antibody $(C$ and $D)$ followed by FITC-labeled anti-rabbit $\mathrm{IgG}$ as described in the test. $A$ and $B, \times 1900 ; C$ and $D, \times 900$. 
was visible in the zona glomerulosa $(\mathrm{Zg})$ (Fig. $4 \mathrm{~A}$ ), and little to no signal was present in the adrenal medulla (data not shown). The adrenal cell size increased after estrogen treatment (compare Fig. 4, $A$ and $B$, which were both photographed at the same magnification) and this increase in size was associated with an increase in staining intensity within the zona fasciculata. The staining appeared to be uniform in intensity on all aspects of the adrenal sinusoidal surfaces. When adjacent sections were stained with a rabbit anti-rat polyclonal apo AI antibody (Fig. 4, $C$ and $D$ ), a virtually identical staining pattern was seen. The intensity of the apo AI signal increased after estrogen treatment and its distribution remained identical to that of SR-BI (Fig. 4, $B$ and $D$ ). Tissue staining of other sections from the same adrenal glands with an LDLR antibody revealed a distribution of staining similar to SR-BI except that the staining extended further into the zona glomerulosa (Fig. 4 $E$ ). Again, the signal increased after estrogen treatment (Fig. 4 $F$ ). These results were consistent with the results of the immunoblot analysis of SR-BI and of the LDLR in adrenal membranes (Fig. 3).

In the unstimulated ovary, SR-BI staining was seen in the theca externa and interna layers of the secondary follicles, as well as the theca interna of the graafian follicles (data not shown). SR-BI was also detectable in the granulosa cells of the corpus luteum (Fig. $5 A$ ). Estrogen treatment caused an $\sim 60 \%$ increase in ovarian weight, with a visible increase in the size and number of follicles. Estrogen also enhanced the development of the progesterone-producing corpus luteal cells. After estrogen treatment, SR-BI staining increased dramatically in the granulosa cells of the corpus luteum $(C L)$ but not in the adjacent follicle $(F)$ (Fig. $5 \mathrm{~B}$ ). A more modest increase in LDLR signal was also seen in the treated corpus luteum (Fig. 5 $D)$. The theca cell layers seemed to have significantly lower SR-BI staining after estrogen treatment. This apparent decrease in SR-BI staining in nonluteal cells of the estrogentreated ovary, concurrent with the dramatic increase in SR-BI staining in the corpus luteum, may help explain the lack of change in SR-BI levels when whole ovaries of animals treated with and without estrogen were analyzed by immunoblotting (Fig. 3). This result may be due to estrogen-induced increases in the number of cells expressing little or no SR-BI associated with follicular development and/or a decrease in the SR-BI expression in the nonluteal cells of the ovary.

There was little or no detectable immunostaining of hepatic tissues either without or with estrogen treatment using the anti-SR-BI antibody (Fig. 6, $A$ and $B$ ). This result was ei-

\section{ESTROGEN -}
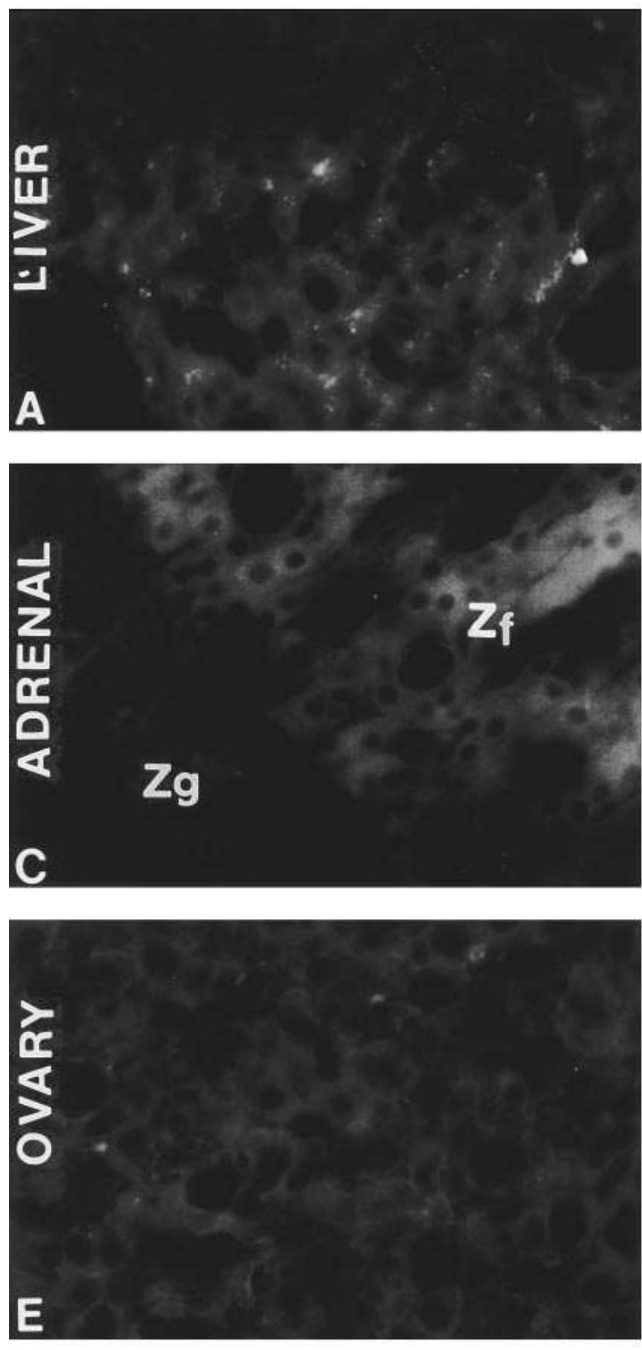

\section{ESTROGEN +}
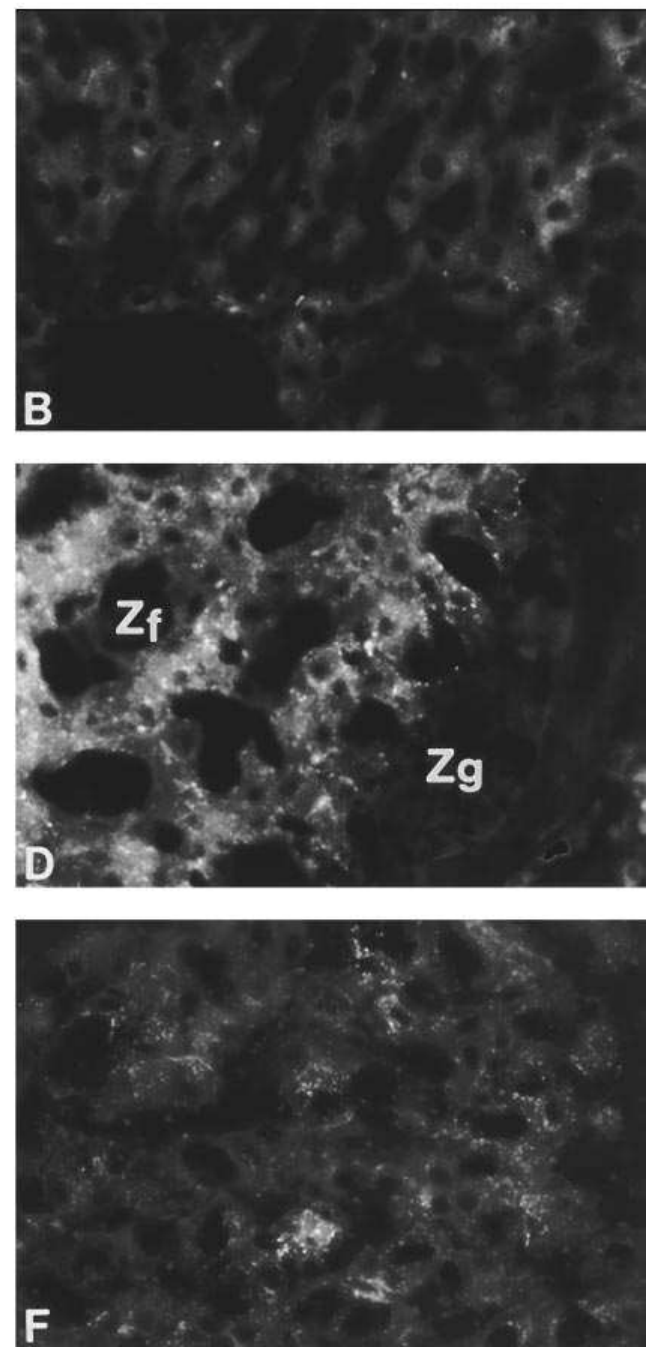

Figure 7. Tissue uptake of DiIlabeled HDL lipids. Shaminjected $(A, C$, and $E$ ) or estrogen-treated $(B, D$, and $F)$ rats were injected with an intravenous bolus of DiI-labeled HDL into the jugular vein. $1 \mathrm{~h}$ after the injection, the animals were perfused and the tissues were fixed and processed for frozen sectioning. Sections were mounted on glass slides and observed immediately using a filter package for rhodamine. $Z f$, zona fasciculata, $Z g$, zona glomerulosa. $E$ and $F$ show corpus luteum only. $\times 900$. 
ther due to lower levels of SR-BI expressed in individual hepatocytes or to inaccessibility of the peptide epitope to the antibody in this tissue. Hepatic SR-BI expression in the liver may not be limited to a specific cell type, as is the case in the adrenal gland and ovary, but rather may be expressed at a low level in cells throughout the organ. This explanation is supported by our finding that it was also very difficult to detect LDLR immunofluorescence in the hepatocytes of the sham-injected animal (Fig. $6 \mathrm{C}$ ). As expected from the immunoblot analysis (Fig. 3), a dramatic increase in immunodetectable LDLR was seen on liver sinusoidal surfaces after estrogen treatment (Fig. 6, compare $C$ and $D$ ). Previous studies by Anderson and his colleagues have established that hepatic LDLRs are primarily expressed on the sinusoidal surfaces of hepatocytes (45).

Uptake of DiI-labeled HDL-associated lipids in tissues of estrogen-treated animals. To examine the effect of estrogen treatment on the uptake of lipid from HDL, DiI-labeled HDL was infused into the sham-injected and estrogen-treated animals $1 \mathrm{~h}$ before death. DiI is a fluorescent lipid that has been used to follow the fates of the lipid components of both LDL and HDL in vitro and in vivo $(4,36)$. In the liver of the shaminjected animals (Fig. $7 \mathrm{~A}$ ), a very low level of diffuse fluorescence, as well as punctate intracellular staining, was seen in association with the hepatocytes. The significance of this low level of staining is unclear. The amount of staining did not change significantly after estrogen treatment (Fig. $7 \mathrm{~B}$ ). If all of the DiI from the HDL was transferred to cells via SR-BI, a decrease in DiI-labeling would be expected in the estrogentreated liver, since the level of SR-BI is virtually undetectable in the liver of estrogen-treated animals (Fig. 3). The absence of any detectable fall in fluorescence staining in the estrogentreated animals raises the possibility that there may be addi-

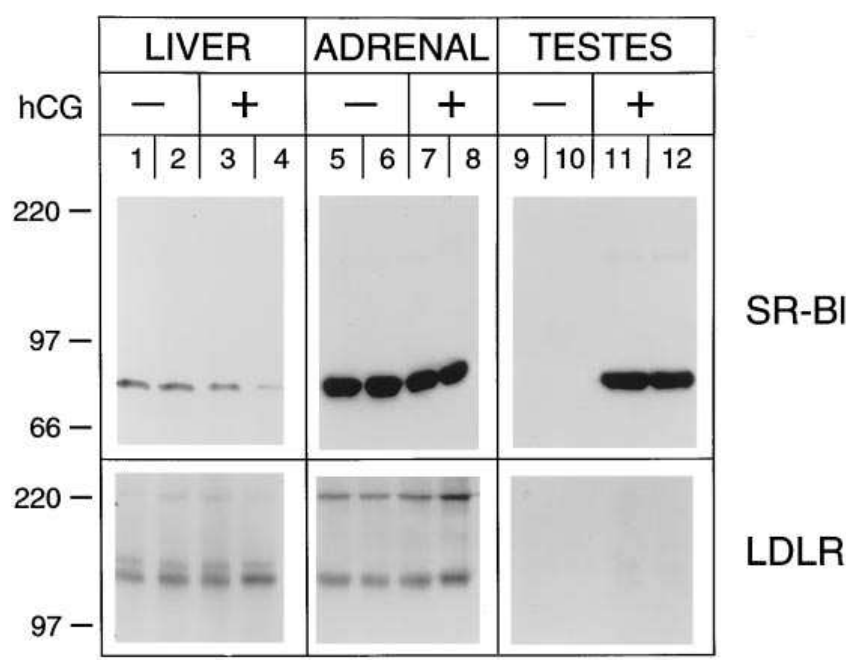

Figure 8. Immunoblot analysis of SR-BI protein in the liver, adrenal glands, and testes of male sham and hCG-treated rats. In the upper panels, levels of SR-BI protein were analyzed in reduced membrane fractions of liver (lanes 1-4), adrenal glands (lanes 5-8), and testes (lanes 9-12) from four male rats treated with $(+)$ or without $(-)$ hCG. SR-BI was detected using anti-SR-BI antibody (IgG-495). In the lower panels, the same fractions were analyzed for LDLR content by immunoblotting with anti-LDLR antibody under nonreducing conditions. A total of $15 \mu \mathrm{g}$ of adrenal membrane protein was loaded in upper panel lanes 5-8. All other lanes contain $50 \mu \mathrm{g}$ of membrane protein. tional SR-BI-independent mechanisms allowing for a low level of HDL-associated lipids to enter hepatocytes. Alternative mechanisms include uptake of HDL lipid directly via other receptors or in vivo transfer of DiI to other lipoproteins before tissue uptake. In addition, given the low level of signal in the sham-injected animals, a further decrease would have been difficult to detect using these methods.

In contrast to these effects in the liver, estrogen treatment induced an increase in the uptake of DiI from DiI-HDL in the adrenal gland (Fig. 7, $C$ and $D$ ). The uptake was restricted to the same regions of the adrenal gland that expressed SR-BI and bound apo AI, i.e., the zona fasciculata and the zona reticularis. An increase in both diffuse and punctate fluorescence staining was seen in the cytoplasm of the adrenal cells of the estrogen-treated animals (Fig. $7 \mathrm{D}$ ), compared with the shaminjected animals (Fig. $7 \mathrm{C}$ ). An increase in intracellular punctate fluorescence was also seen in the ovarian corpus luteal cells after estrogen treatment (Fig. 7 compare $E$ and $F$ ). Thus, in these two steroidogenic tissues, the cell-type specific increases in immunodetectable SR-BI were associated with an increase in the delivery of fluorescent DiI-lipid from HDL to the tissues.

It could be argued that the estrogen-induced increase in the uptake of HDL-derived lipid into these two tissues is not causally related to the increase in SR-BI protein, but rather due to the infusion of the DiI-labeled HDL into a greatly reduced endogenous HDL pool in the estrogen-treated animals (see Table I and Fig. 2). However, the substantial estrogen-induced increase in immunoreactive apo AI, and thus HDL, in the adrenal glands (see Fig. 4), indicates that the size of the pool of HDL within the adrenal gland was not reduced, but rather increased by the hormone. We cannot rule out that some of the fluorescence staining in these tissues results from uptake of HDL via the LDLR, if some of the infused HDL acquired apo E during circulation. However, given the very low levels of apo E circulating in the plasma of the estrogen-treated rat (Fig. 2 $B$ ), and the absence of any increase in fluorescence staining in the liver despite the dramatic increase in immunodetectable LDLR (Fig. 6), it seems unlikely that the LDLR is playing a major role in mediating the entry of HDL-associated lipids into these tissues.

Effect of hCG on testicular SR-BI expression. The profound effect of estrogen on plasma lipoprotein levels in rats complicates efforts to define the mechanism by which SR-BI is regulated. Testicular HDL-cholesteryl ester uptake and binding has been previously demonstrated to be stimulated by hCGtreatment although, unlike estrogen, hCG has no significant effect on the plasma levels of cholesterol $(13,31)$. Therefore, we examined SR-BI levels in sham- and hCG-treated animals by immunoblot analysis (Fig. 8) and indirect immunofluorescence studies (Fig. 9). Animals treated for $4 \mathrm{~d}$ with $250 \mathrm{U} / \mathrm{kg}$ hCG had plasma cholesterol levels of $66 \pm 6 \mathrm{mg} / \mathrm{dl}$ as compared with $74 \pm 9 \mathrm{mg} / \mathrm{dl}$ in the sham-treated counterparts. Fig. 8 shows that hCG treatment induced a dramatic increase in testicular SR-BI, but did not substantially alter its expression in the liver or adrenal gland. Treatment with hCG was associated with a modest, but detectable (on long exposure, not shown) increase in LDLR levels. The very low levels of immunodetectable SR-BI and LDLR in the sham-injected animals is probably due to the fact that the Leydig cells comprise only $1 \%$ of the testicular cellular mass. Immunofluorescence analysis of testes in the hCG-treated rats is consistent with this ex- 

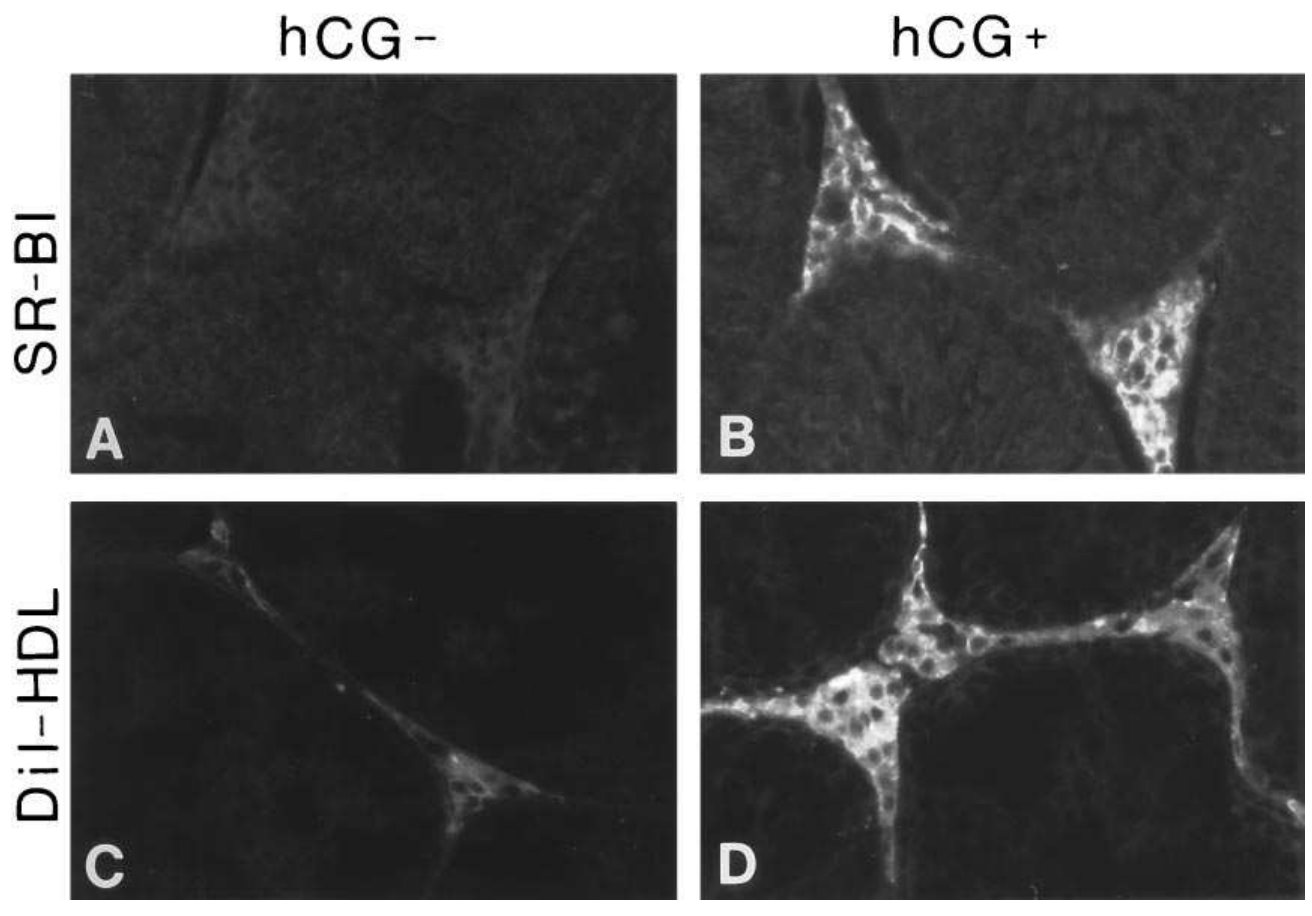

Figure 9. Immunolocalization of SR-BI and DiI-HDL uptake in rat testes from sham-injected ( $A$ and $C$ ) and hCG-injected ( $B$ and $D$ ) rats. Sections were incubated with anti-SR-BI antibody followed by FITC-labeled antirabbit $\mathrm{IgG}$, as described in Methods ( $A$ and $B)$. Shaminjected $(C)$ or hCG-treated rats $(D)$ were given with an intravenous bolus of DiI-HDL and the testes were harvested $1 \mathrm{~h}$ after injection. Tissue samples were processed as described in Fig. 7.

planation, because the dramatic increase in SR-BI expression was exclusively localized to the steroidogenic Leydig cells (Fig. 9, $A$ and $B$ ). To determine whether the increase in SR-BI was associated with an increase in the association of HDL with Leydig cells, we infused DiI-labeled HDL into the sham-injected and hCG-treated animals. An increase in fluorescent staining was seen associated with the Leydig cells in the hCG-treated animals (Fig 9, $C$ and $D$ ).

\section{Discussion}

In this study we have used immunoblotting and immunofluorescence microscopy to examine the expression and hormonal regulation of SR-BI in rodents. The highest levels of SR-BI expression were in the zona fasciculata and zona reticularis of the adrenal gland, and the thecal and corpus luteal cells of the ovary. The liver and the mammary gland had significant levels of SR-BI protein, although the cell-specific distribution of expression in these tissues was not defined. The adrenal gland, ovary, and liver have been previously shown to be capable of selective uptake of HDL-cholesteryl ester $(8,9)$ and evidence presented here supports the notion that SR-BI is a receptor mediating this process. In the mammary gland of the pregnant rat, SR-BI may serve another purpose, possibly participating in the transfer of lipids from plasma lipoproteins into milk.

The other major finding of this study is that SR-BI expression in the liver, adrenal gland, ovary, and testes was subject to regulation by high-dose estrogen or hCG treatment in a tissueand cell-type-specific fashion. In rats, estrogen treatment induced a fall in hepatic SR-BI protein levels and a dramatic increase in SR-BI levels in the steroidogenic cells of the adrenal gland and ovary. These observations are consistent with prior in vivo studies that showed high-dose estrogen treatment in the rat is associated with increased selective uptake of HDLcholesteryl esters in the adrenal gland and ovary but slightly decreased uptake by the liver (30). SR-BI levels also increased dramatically in the Leydig cells of the testes after hCG administration. Taken together, these findings strongly implicate SR-BI as a physiologically relevant HDL receptor, as was previously proposed (4).

Prior studies have implicated the rat adrenal gland as a major site of HDL receptor activity (8, 9, 13-17, 32-34). Compared to the rabbit and hamster, the rat produces extremely large amounts of adrenal corticosteroids, yet the relative rate of cholesterol synthesis in the adrenal is much lower than in the other two species (17). Therefore, the rat adrenal gland must obtain the cholesterol to support this high level of adrenal steroidogenesis from circulating lipoproteins $(17,26)$. Some of the cholesterol enters the adrenal cell via the LDLR, which binds to and internalizes apo E-containing HDL as well as LDL. Male rats made hypolipidemic by treatment with estrogen, or alternatively with 4-aminopyrazolo-(3, 4-d) pyrimidine (4APP) (an inhibitor of hepatic lipoprotein production), have a significant increase in the number of LDLRs in the adrenal gland, and as expected, an increased uptake of LDL-C (46). We show that after estrogen treatment, the increase in adrenal LDLR number is also associated with an increase in adrenal SR-BI. Since SR-BI can mediate selective uptake of HDL-cholesteryl esters into cells in vitro (4) the increase in SR-BI in vivo may well explain the enhancement of selective uptake of HDL-cholesteryl esters in the adrenal of the estrogen-treated rat (30). Because SR-BI can also bind LDL with high affinity (2), stimulation of expression by estrogen may also contribute to estrogen-enhanced adrenal metabolism of LDL.

Despite the almost undetectable levels of HDL in the plasma of the estrogen-treated rats, abundant endogenous apo AI was present in the zona reticularis and zona fasciculata of the adrenal in exactly the same location as SR-BI, providing strong evidence that SR-BI is an adrenal HDL receptor. In a series of elegant localization studies, Reaven, Azhar, and their colleagues (47) have shown that both HDL and LDL particles become trapped in channels that form from microvillar exten- 
sions from the sinusoidal surfaces of adrenal cells. It will be interesting to perform higher resolution morphological studies to determine if there is a specific association of these lipoproteins with SR-BI on the microvillar surfaces.

The ovary also actively takes up HDL-cholesteryl ester for steroidogenesis $(8,9,13,14,48,49)$. The expression pattern and regulation of SR-BI in the ovary was more complex than that in the adrenal gland. In the sham-injected rats, SR-BI was expressed in the thecal cells and also, at low levels, in granulosa cells. The expression of SR-BI in the thecal cells is consistent with their active steroidogenic role in the unstimulated ovary (13). After estrogen stimulation, the level of SR-BI staining associated with the thecal cells that surround the developing follicle appeared to fall, while a pronounced increase in signal was seen in the granulosa-derived corpus luteal cells, the cells that synthesize and secrete progesterone. These results are consistent with prior studies that have shown that hormonal stimulation (either with estrogen or hCG) is associated with depletion of luteal cell cholesteryl ester content and an increase in cell surface HDL binding sites $(50,51)$. Like the adrenal cells of the zona fasiculata, the corpus luteal cells also have an intricate system of microvilli on their cell surface which form lipoprotein-filled channels (52-54); it is likely that SR-BI resides within these specialized structures.

Although the highest rates of selective uptake of HDLcholesteryl ester occur in the adrenal gland and ovary, the largest amount of uptake occurs in the liver (9). However, unlike the adrenal gland and corpus luteum of the ovary, high-dose estrogen treatment was associated with a fall in hepatic SR-BI expression. The suppression of hepatic SR-BI associated with estrogen treatment of the rat may serve to reroute the HDL selective uptake pathway away from the liver to the adrenal gland and ovary, to ensure maintenance levels of reproductive and stress hormones in the face of severe hypocholesterolemia. The mechanism responsible for the decrease in hepatic $\mathrm{SR}-\mathrm{BI}$ is not known, but given the reciprocal changes in levels of SR-BI in the rat liver versus the adrenal gland and corpus luteal cells of the ovary, it seems unlikely that estrogen directly regulates SR-BI expression.

The signaling mechanism responsible for the tissue and cell-specific changes in SR-BI remains to be defined. In the estrogen-treated rat, both the adrenal gland and ovary are subjected to very low levels of circulating plasma lipoproteins. Active steroidogenesis would rapidly deplete endogenous cholesterol ester stores in these tissue, and thus make them dependent on de novo cholesterol synthesis and/or the import of exogenous lipoproteins to maintain hormone biosynthesis. Intracellular cholesterol levels are known to regulate LDLR activity (5), and they may also play a role in controlling SR-BI expression. A unifying hypothesis is that, in at least some tissues, SR-BI levels are dictated by cellular demands for cholesterol (or one of its derivatives).

It is also possible that trophic hormones play a primary role in regulating SR-BI expression in the estrogen-treated rat. Both ACTH and luteinizing hormone (LH) are associated with an increase in HDL binding and selective HDL-cholesteryl ester uptake by rat adrenal glands $(34,46)$, ovaries $(49$, 50), and testes (31). Kovanen et al. (46) showed that hypolipoproteinemia and ACTH together were both required to induce a dramatic elevation in adrenal ${ }^{125}$ I-HDL uptake in the mouse. Similarly, no increase in ${ }^{125} \mathrm{I}-\mathrm{HDL}$ binding to corpus luteal cells occurred in hypophysectomized rats which were estrogen- treated unless the animals were also treated with LH (48). Further studies will be required to define whether the estrogen-induced changes in SR-BI levels are the effect of a trophic or some other hormone or are due to depletion of cholesterol ester stores in steroidogenic tissues. The recent finding that hypophysectomized rats have a dramatic decrease in immunodetectable SR-BI in the adrenal gland (Wyne, K., and H.H. Hobbs, unpublished observations) and that chronic estrogen therapy in rats affects ACTH secretion (55) strongly suggest that trophic hormones play a key role in the regulation of this receptor.

The numerous effects of estrogen on plasma lipoprotein levels, hepatic function, and pituitary function, led us to directly assess the effects of a trophic hormone on SR-BI expression in rat testes, where HDL-cholesterol is the preferred source for sterol synthesis (14). We treated rats with hCG, a potent inducer of testosterone synthesis in Leydig cells and found that administration of hCG increased SR-BI expression over 20-fold in the testes, despite no associated changes in the levels of plasma lipoproteins. The increase in SR-BI was localized to the Leydig cells, which strongly suggests that the Leydig cells of the rat also obtain HDL-cholesteryl esters for steroidogenesis via SR-BI. These findings are consistent with those of Chen et al. (31) who found an increase in the amount of radiolabeled HDL associated with Leydig cells after hCG administration. Whether hCG stimulates SR-BI expression directly or indirectly, by stimulating testosterone synthesis and thus depleting testicular stores of cholesterol ester, remains to be determined, but it is clear that dramatic increases in SR-BI can occur as a specific response to a trophic hormone in the absence of hypolipidemia. We are currently conducting similar studies to examine the effects of ACTH on SR-BI expression in the adrenal gland.

In contrast to the results in the rat, estrogen had only small effects on SR-BI expression in the mouse. In the mouse, high dose estrogen treatment had no effect on hepatic LDLR levels and was associated with no changes in SR-BI in the liver, adrenal, or ovary. Unlike the rat, the estrogen-treated mouse had only modest changes in plasma cholesterol $(150 \pm 6$ vs $115 \pm 7$ $\mathrm{mg} / \mathrm{dl})$ and triglycerides $(76 \pm 7$ and $72 \pm 9 \mathrm{mg} / \mathrm{dl}$ ), which is consistent with previous reports (56). Estrogen treatment induced a slight increase in the level of immunodetectable SR-BI and no change in the level of LDLR in the livers of these mice (data not shown). No significant changes in SR-BI or LDLR levels were found in the adrenal gland or ovary after estrogen treatment (data not shown). The results of immunofluorescence localization in the mouse tissue were consistent with the Western blot results; there were no estrogen-induced differences in the levels of SR-BI or the LDLR in the adrenal gland or ovary (data not shown). Thus, in mice, where pharmacological doses of estrogen have only a modest effect on plasma lipoproteins and no effect on hepatic LDLR expression, there was little estrogen-induced change in tissue levels of SR-BI. The absence of any change in SR-BI in response to estrogen in the mouse established that estrogen-induced regulation of SR-BI expression can vary enormously in different species. This was not surprising since the effects of estrogen treatment on lipoprotein metabolism differ significantly between species. Rat, rabbits, and humans are sensitive, whereas mice are relatively resistant to the effects of estrogen on plasma lipoprotein levels (25-29, 56, 57).

The amount of estrogen administered to the rodents in these studies was supra-physiologic. Our results suggest that 
physiological levels of estrogen may also have an effect on SR-BI levels in some species. Compared to males, female rats had modestly lower steady-state levels of immunodetectable SR-BI in the liver and higher levels in the adrenal gland (data not shown). In humans, estrogen treatment of postmenopausal women results in a significant increase in HDL-C and decrease in LDL-C (58). Estrogen treatment is also associated with an increase in catabolism of ${ }^{125} \mathrm{I}-\mathrm{LDL}$ (58), perhaps because of stimulation of the hepatic LDLR activity as seen in the rat. The mechanism responsible for the higher plasma HDL-C levels in estrogen-treated postmenopausal and premenopausal women has not been clearly defined. The hepatic synthesis rate of apo AI is higher in estrogen-treated women, and this may contribute to the increased plasma HDL-C levels (59). In addition, if estrogen suppresses hepatic SR-BI expression in humans as it does in rats, this might directly or indirectly contribute to the higher HDL-C levels in females.

It seems likely that one important function of SR-BI is supplying substrate for steroidogenesis. SR-BI may also play a role in supplying substrate for hepatic bile acid synthesis and possibly even in reverse cholesterol transport. Additional studies will be required to directly address the function of SR-BI in the liver. The quantitative significance of SR-BI-mediated HDL-C uptake may depend critically on the species examined. For example, in rabbits, LDL rather than HDL, appears to be the major source of cholesterol for adrenal steroidogenesis (17), thus SR-BI may be less important than the LDLR for this process. Alternatively, SR-BI may contribute to adrenal metabolism of LDL, since it has been shown in vitro that SR-BI can bind LDL (2).

The role of SR-BI in cholesterol transport and steroidogenesis in humans remains to be established. Selective uptake of HDL-cholesteryl esters has been demonstrated in primary culture of human hepatocytes (60) but its relative role in the transport of cholesterol from tissues to the liver in vivo in humans is not known. Based on in vitro studies, it appears that the LDLR is the major gateway through which cholesterol is provided to satisfy the very high cholesterol requirements of human fetal adrenal cells (61). However, little is known about the relative importance of LDL and HDL pathways for adult adrenal gland function. Humans with abetalipoproteinemia, who have little to no apo B100-containing lipoproteins, show no evidence of adrenal insufficiency, unless they are subjected to prolonged exposure to ACTH (62); similarly, women with abetalipoproteinemia produce reduced levels of progesterone during the luteal phase of the menstrual cycles (63) but sufficient amounts of sex steroids to maintain pregnancies. Individuals with homozygous familial hypercholesterolemia, who have little or no LDL receptor activity, do not have a defect in plasma cortisol response to ACTH unless maximally stimulated (64). The relative roles of adrenal, ovarian, and testicular cholesterol biosynthesis and cholesterol uptake via SR-BI, or other LDLR-independent pathways, in these individuals are not known. In humans, SR-BI may serve as either a primary or a back-up system to ensure maintenance of cholesterol delivery to both the adrenal gland and ovary. We have recently found that SR-BI is expressed at high levels in both the adrenal gland and liver of humans (Wyne, K., and H.H. Hobbs, unpublished observations). The importance of SR-BI in cholesterol transport and steroidogenesis in humans, including its relative role in the absence or presence of functional LDLRs, awaits further study.

\section{Acknowledgments}

We wish to thank Melissa Christiansen and Tommy Hyatt for the excellent technical assistance and Michael S. Brown, Laura Woollett, Jonathan Cohen, David Russell, and Joseph L. Goldstein for helpful discussions. We also thank Susan Acton for assistance in preparing antibody and lipoprotein reagents.

This work was supported by the National Institutes of Health (HL-20948, HL41484, and HL52212), the Perot Family Fund, and the W.M. Keck Foundation. A. Rigotti is a Howard Hughs Medical Institute Postdoctoral fellow.

\section{References}

1. Eisenberg, S. 1984. High density lipoprotein metabolism. J. Lipid Res. 25: 1017-1058.

2. Acton, S.L., P.E. Scherer, H.F. Lodish, and M. Krieger. 1994. Expression cloning of SR-BI, a CD36-related class B scavenger receptor. J. Biol. Chem. 269:21003-21009.

3. Rigotti, A., S.L. Acton, and M. Krieger. 1995. The class B scavenger receptors SR-BI and CD36 are receptors for anionic phospholipids. J. Biol. Chem. 270:16221-16224.

4. Acton, S., A. Rigotti, K.T. Landschulz, S. Xu, H.H. Hobbs, and M. Krieger. 1996. Identification of scavenger receptor SR-BI as a high density lipoprotein receptor. Science (Wash. DC). 271:518-520.

5. Brown, M.S., and J.L. Goldstein. 1986. A receptor-mediated pathway for cholesterol homeostasis. Science (Wash. DC). 232:34-47.

6. Knecht, T.P., and R.C. Pittman. 1989. A plasma membrane pool of cholesteryl esters that may mediate the selective uptake of cholesteryl esters from high-density lipoproteins. Biochim. Biophys. Acta. 1002:365-375.

7. Rinninger, F., S. Jaeckle, and R.C. Pittman. 1993. A pool of reversibly cell-associated cholesteryl esters involved in the selective uptake of cholesteryl esters from high- density lipoproteins by HepG2 hepatoma cells. Biochim. Biophys. Acta. 1166:275-283.

8. Glass, C., R.C. Pittman, M. Civen, and D. Steinberg. 1985. Uptake of high-density lipoprotein-associated apoprotein A-I and cholesterol esters by 16 tissues of the rat in vivo and by adrenal cells and hepatocytes in vitro. J. Biol. Chem. 260:744-750.

9. Glass, C., R.C. Pittman, D.B. Weinstein, and D. Steinberg. 1983. Dissociation of tissue uptake of cholesterol ester from that of apoprotein A-I of rat plasma high density lipoprotein: selective delivery of cholesterol ester to liver, adrenal, and gonad. Proc. Natl. Acad. Sci. USA. 80:5435-5439.

10. Glomset, J.A.. 1968. The plasma lecithin:cholesterol acyltransferase reaction. J. Lipid Res. 9:155-167.

11. Pieters, M.N., D. Schouten, and T.J.C. Van Berkel. 1994. In vitro and in vivo evidence for the role of HDL in reverse cholesterol transport. Biochim. Biophys. Acta. 1225:125-134.

12. Fielding, C.J., and P.E. Fielding. 1995. Molecular physiology of reverse cholesterol transport. J. Lipid Res. 36:211-228.

13. Gwynne, J.T., and J.F. Srauss III. 1982. The role of lipoproteins in steroidogenesis and cholesterol metabolism in steroidogenic gland. Endocr. Rev. 3:299-328.

14. Andersen, J.M., and J.M. Dietschy. 1978. Relative importance of high and low density lipoproteins in the regulation of cholesterol synthesis in the adrenal gland, ovary, and testis of the rat. J. Biol. Chem. 253:9024-9032.

15. Balasubramaniam, S., J.L. Goldstein, J.R. Faust, G.Y. Brunschede, and M.S. Brown. 1977. Lipoprotein-mediated regulation of 3-hydroxy-3-methylglutaryl coenzyme A reductase activity and cholesteryl ester metabolism in the adrenal gland of the rat. J. Biol. Chem. 252:1771-1779.

16. Andersen, J.M., and J.M. Dietschy. 1976. Regulation of sterol synthesis in adrenal gland of the rat by both high and low density human plasma lipoproteins. Biochem. Biophys. Res. Commun. 72:880-885.

17. Spady, D.K., and J.M. Dietschy. 1985. Rates of cholesterol synthesis and low-density lipoprotein uptake in the adrenal glands of the rat, hamster and rabbit in vivo. Biochem. Biophys. Acta. 836:167-175.

18. Kovanen, P.T., W.J. Schneider, G.M. Hillman, J.L. Goldstein, and M.S Brown. 1979. Separate mechanisms for the uptake of high and low density lipoproteins by mouse adrenal gland in vivo. J. Biol. Chem. 254:5498-5505.

19. Stein, Y., Y. Dabach, G. Hollander, G. Halperin, and O. Stein. 1983. Metabolism of HDL-cholesteryl ester in the rat, studied with a nonhydrolyzable analog, cholesteryl linoleyl ether. Biochim. Biophys. Acta. 752:98-105.

20. Leitersdorf, E., O. Stein, S. Eisenberg, and Y. Stein. 1984. Uptake of rat plasma HDL subfractions labeled with $\left[{ }^{3} \mathrm{H}\right]$ cholesteryl linoleyl ether or with

${ }^{125} \mathrm{I}$ by cultured rat hepatocytes and adrenal cells. Biochim. Biophys. Acta. 796: $72-82$.

21. Pittman, R.C., T.P. Knecht, M.S. Rosenbaum, and C.A. Taylor, Jr. 1987. A nonendocytotic mechanism for the selective uptake of high density lipoprotein-associated cholesterol esters. J. Biol. Chem. 262:2443-2450.

22. Rinninger, F., M. Brunder, S. Jäckle, T. Kaiser, and H. Greten. 1995. Se- 
lective uptake of low-density lipoprotein-associated cholesteryl esters by human fibroblasts, human HepG2 hepatoma cells and J774 macrophages in culture. Biochim. Biophys. Acta. 1255:141-153.

23. Wenger, N.K., L. Speroff, and B. Packard. 1993. Cardiovascular health and disease in women. N. Engl. J. Med. 329:247-256.

24. Nabulsi, A.A., A.R. Folsom, A. White, W. Patsch, G. Heiss, K.K. Wu, and M. Szklo. 1993. Association of hormone-replacement therapy with various cardiovascular risk factors in postmenopausal women. N. Engl. J. Med. 328: 1069-1075.

25. Davis, R.A., and P.S. Roheim. 1978. Pharmacologically induced hypolipidemia. The ethinyl estradiol-treated rat. Atherosclerosis. 30:293-299.

26. Verschoor-Klootwyk, A.H., L. Vershoor, S. Azhar, and G.M. Reaven. 1982. Role of exogenous cholesterol in regulation of adrenal steroidogenesis in the rat. J. Biol. Chem. 257:7666-7671.

27. Kovanen, P.T., M.S. Brown, and J.L. Goldstein. 1979. Increased binding of low density lipoprotein to liver membranes from rats treated with $17 \alpha$-ethinyl estradiol. J. Biol. Chem. 254:11367-11373.

28. Windler, E.E.T., P.T. Kovanen, Y.-S. Chao, M.S. Brown, R.J. Havel, and J.L. Goldstein. 1980. The estradiol-stimulated lipoprotein receptor of rat liver. A binding site that mediates the uptake of rat lipoproteins containing apoproteins B and E. J. Biol. Chem. 255:10464-10471.

29. Chao, Y.-S., E.E. Windler, G.C. Chen, and R.J. Havel. 1979. Hepatic catabolism of rat and human lipoproteins in rats treated with $17 \alpha$-ethinyl estradiol. J. Biol. Chem. 254:11360-11366.

30. Rinninger, F., and R.C. Pittman. 1987. Regulation of the selective uptake of high density lipoprotein-associated cholesteryl esters. J. Lipid Res. 28: 1313-1325.

31. Chen, Y.-D.I., F.B. Kraemer, and G.M. Reaven. 1980. Identification of specific high density lipoprotein-binding sites in rat testis and regulation of binding by human chorionic gonadotropin. J. Biol. Chem. 255:9162-9167.

32. Azhar, S., Stewart D., and E. Reaven. 1989. Utilization of cholesterolrich lipoproteins by perfused rat adrenals. J. Lipid Res. 30:1799-1810.

33. Gwynne, J.T., and D.D. Mahaffee. 1989. Rat adrenal uptake and metabolism of high density lipoprotein cholesteryl ester. J. Biol. Chem. 264:81418150 .

34. Gwynne, J.T., D. Mahaffee, H.B. Brewer, Jr., and R.L. Ney. 1976. Adrenal cholesterol uptake from plasma lipoproteins: Regulation by corticotropin. Proc. Natl. Acad. Sci. USA. 73:4329-4333.

35. Nestler, J.E., M. Bamberger, G.H. Rothblat, and J.F. Strauss III. 1985. Metabolism of high density lipoproteins reconstituted with $\left[{ }^{3} \mathrm{H}\right]$ cholesteryl ester and $\left[{ }^{14} \mathrm{C}\right]$ cholesterol in the rat, with special reference to the ovary. Endocrinology. 117:502-510.

36. Pitas, R.E., T.L. Innerarity, J.N. Weinstein, and R.W. Mahley. 1981. Acetoacetylated lipoproteins used to distinguish fibroblasts from macrophages in vitro by fluorescence microscopy. Arteriosclerosis. 1:177-185.

37. Jokinen, E.V., K.T. Landschulz, K.L. Wyne, Y.K. Ho, P.K. Frykman, and H.H. Hobbs. 1994. Regulation of the very low density lipoprotein receptor by thyroid hormone in rat skeletal muscle. J. Biol. Chem. 269:26411-26418.

38. Herz, J., R.C. Kowal, Y.K. Ho, M.S. Brown, and J.L. Goldstein. 1990. Low density lipoprotein receptor-related protein mediates endocytosis of monoclonal antibodies in cultured cells and rabbit liver. J. Biol. Chem. 265:2135521362.

39. Herz, J., J.L. Goldstein, D.K. Strickland, Y.K. Ho, and M.S. Brown. 1991. 39-kDa protein modulates binding of ligands to low density lipoprotein receptor-related protein $/ \alpha_{2}$-macroglobulin receptor. J. Biol. Chem. 266:2123221238.

40. Willnow, T.E., Z. Sheng, S. Ishibashi, and J. Herz. 1994. Inhibition of hepatic chylomicron remnant uptake by gene transfer of a receptor antagonist. Science (Wash. DC). 264:1471-1474.

41. Ishibashi, S., M.S. Brown, J.L. Goldstein, R.D. Gerard, R.E. Hammer, and J. Herz. 1993. Hypercholesterolemia in low density lipoprotein receptor knockout mice and its reversal by adenovirus-mediated gene delivery. J. Clin. Invest. 92:883-893.

42. Pathak, R.K., M. Yokode, R.E. Hammer, S.L. Hofmann, M.S. Brown, J.L. Goldstein, and R.G. Anderson. 1990. Tissue-specific sorting of the human LDL receptor in polarized epithelia of transgenic mice. J. Cell Biol. 111:347359.

43. Wyne, K.L., R.K. Pathak, M.C. Seabra, and H.H. Hobbs. 1996. Expres- sion of the very low density lipoprotein receptor in endothelial cells. Arterio. Thromb. Vas. Biol. 16:407-415.

44. Krieger, M., and J. Herz. 1994. Structures and functions of multiligand lipoprotein receptors: macrophage scavenger receptors and LDL receptor-related protein (LRP). Annu. Rev. Biochem. 63:601-637.

45. Pathak, R.K., M. Yokode, R.E. Hammer, S.L. Hofmann, M.S. Brown, J.L. Goldstein, and R.G.W. Anderson. 1990. Tissue-specific sorting of the human LDL receptor in polarized epithelia of transgenic mice. J. Cell Biol. 111: 347-359.

46. Kovanen, P.T., J.L. Goldstein, D.A. Chappell, and M.S. Brown. 1980. Regulation of low density lipoprotein receptors by adrenocorticotropin in the adrenal gland of mice and rats in vivo. J. Biol. Chem. 255:5591-5598.

47. Reaven, E., M. Spicher, and S. Azhar. 1989. Microvillar channels: a unique plasma membrane compartment for concentrating lipoproteins on the surface of rat adrenal cortical cells. J. Lipid Res. 30:1551-1560.

48. Strauss J.F., III, L.C. MacGregor, and J.T. Gwynne. 1982. Uptake of high density lipoproteins by rat ovaries; in vivo direct correlation of high density lipoprotein uptake and steroidogenic activity. J. Steroid Biochem. 16:525531

49. Hwang, J., and K.M. Menon. 1983. Characterization of low density and high density lipoprotein receptors in the rat corpus luteum and regulation by gonadotropin. J. Biol. Chem. 258:8020-8027.

50. Gibori, G., Y.-D. Chen, I. Khan, S. Azhar, and G.M. Reaven. 1984. Regulation of luteal cell lipoprotein receptors, sterol contents, and steroidogenesis by estradiol in the pregnant rat. Endocrinology. 114:609-617.

51. Ghosh, O.K., and K.M.J. Menon. 1987. Induction of high-density-lipoprotein receptors in rat corpus luteum by human choriogonadotropin. Biochem. J. 244:471-479.

52. Reaven, E., J. Boyles, M. Spicher, and S. Azhar. 1988. Evidence for surface entrapment of cholesterol-rich lipoproteins in luteinized ovary. Arteriosclerosis. 8:298-309.

53. Reaven, E., X.-Y. Shi, and S. Azhar. 1990. Interaction of lipoproteins with isolated ovary plasma membranes. J. Biol. Chem. 265:19100-19111.

54. Reaven, E., L. Tsai, and S. Azhar. 1995. Cholesterol uptake by the 'selective' pathway of ovarian granulosa cells: early intracellular events. J. Lipid Res. 36:1602-1617.

55. Burgess, L.H., and R.J. Handa. 1992. Chronic estrogen-induced alterations in adrenocorticotropin and corticosterone secretion, and glucocorticoid receptor-mediated function in female rats. Endocrinology. 131:1261-1269.

56. Srivastava, R.A.K., D. Baumann, and G. Schonfeld. 1993. In vivo regulation of low-density lipoprotein receptors by estrogen differs at the post-transcriptional level in rat and mouse. Eur. J. Biochem. 216:527-538.

57. Ma, T.S., T. Yamamoto, J.L. Goldstein, and M.S. Brown. 1986. Increased mRNA for low density lipoprotein receptor in livers of rabbits treated with $17 \alpha$-ethinyl estradiol. Proc. Natl. Acad. Sci. USA. 83:792-796.

58. Walsh, B.M., I. Schiff, B. Rosner, L. Greenberg, V. Ravnikar, and F.M. Sacks. 1991. Effects of postmenopausal estrogen replacement on the concentrations and metabolism of plasma lipoproteins. N. Engl. J. Med. 325:1196-1204.

59. Schaefer, E.J., D.M. Foster, L.A. Zech, F.T. Lindgren, H.B. Brewer, Jr. and R.I. Levy. 1983. The effects of estrogen administration on plasma lipoprotein metabolism in premenopausal females. J. Clin. Endocrinol. Metab. 57:262267.

60. Rinninger, F., M. Brundert, S. Jäckle, P.R. Galle, C. Busch, J.R. Izbicki, X. Rogiers, D. Henne-Bruns, B. Kremer, C.E. Broelsch, and H. Greten. 1994. Selective uptake of high-density lipoprotein-associated cholesteryl esters by human hepatocytes in primary culture. Hepatology. 19:1110-1114.

61. Carr, B.R., and E.R. Simpson. 1981. Lipoprotein utilization and cholesterol synthesis by the human fetal adrenal gland. Endocr. Rev. 2:306-326.

62. Illingworth, D.R., T.A. Kenny, W.E. and E.S. Orwoll. 1982. Corticosteroid production in abetalipoproteinemia: evidence for an impaired response to ACTH. J. Lab. Clin. Med. 100:115-126.

63. Illingworth, D.R., D.K. Corbin, E.D. Kemp, and E.J. Keenan. 1982. Hormone changes during the menstrual cycle in abetalipoproteinemia: reduced luteal phase progesterone in a patient with homozygous hypobetalipoproteinemia. Proc. Natl. Acad. Sci. USA. 79:6685-6689.

64. Laue, L., J.M. Hoeg, K. Barnes, D.L. Loriaux, and G.P. Chrousos. 1987. The effect of mevinolin on steroidogenesis in patients with defects in the low density lipoprotein receptor pathway. J. Clin. Endocrinol. Metab. 64:531-535. 